\title{
NEVES, André De Jesus. Cibercultura e literatura, identidade e autoria em produçóes culturais participatórias e na literatura de fã (fanfiction).
}

São Paulo, Paco, 2014.

Falar de realidade virtual, hoje, em uma época dominada pela internet e pelas chamadas redes sociais, tornou-se quase um truísmo. Contudo, nem sempre esse assunto é abordado levando em conta suas possíveis relaçóes com outras áreas do conhecimento ou ação humanas, sobretudo as manifestaçôes culturais. Não é o que ocorre com este livro de André de Jesus Neves, escrito originalmente como dissertação de mestrado.

Com efeito, o livro propóe "uma análise do contexto atual da cultura, na mobilidade do contexto da internet e as relaçóes de produção e consumo dos bens culturais, sobretudo literários, no ambiente virtual pelo sujeito contemporâneo" (p. 17). Assim, o autor procura estudar a cultura num mundo marcado pela fragmentação e pela descontinuidade, em especial no espaço virtual (cibercultura), com destaque para a produçáo literária.

Tratando do surgimento da internet, André Neves se apoia em Manuel Castells, a fim de defender a ideia de que a internet se relaciona à cultura de maneira a resultar no que se pode chamar de cultura digital ou cibercultura. Falar em cibercultura, contudo, é referir-se a um espaço de mobilidade, em que valores culturais e sociais estão em constante mudança, como é o espaço virtual, próprio das comunidades virtuais, conceito no qual a noçáo de território físico se desfaz. As comunidades virtuais, por sua vez, seriam coletivos em busca de uma identidade comum, o que sugere a constituição de um novo paradigma social e de uma nova cultura, a "cultura virtual no ciberespaço" (p. 37).

Essa autêntica cultura nômade, relacionada a uma constante fluidez, vincula-se a um novo sentido de mobilidade, interferindo diretamente no meio social: "com a vida no espaço virtual, houve um deslocamento de foco do corpo e da territorialidade na formação das relaçôes sociais e de grande parte das atividades do cotidiano, visto que a onipresença vivenciada no ciberespaço pelo cibernauta o desterritorializa de si mesmo e o faz se perder localmente, na medida em que o re(des)territorializa (virtualmente)" (p. 41). Em suma, a ideia de ciberespaço gera uma nova discussão epistemológica 
do sentido de lugar, interferindo até mesmo no processo de constituição identitária dos indivíduos, já que pressupóe uma busca de identidade coletiva, mas que se dá no espaço virtualizado, lugar onde até mesmo a mediação discursiva é questionada, uma vez que a noção de autoridade, de sujeito do discurso, é colocada sob suspeita nesse espaço. Trata-se, ainda segundo o autor, de um espaço propício à manifestação da voz do subalterno. Nesse sentido, o ciberespaço pode ser entendido como "um lugar de voz, de explosão de significados e reivindicaçóes da cultura marginal, da voz silenciada" (p. 66).

Tais transformaçôes têm incidência direta na questão da subjetividade e, em particular, do autor, que cede lugar a uma espécie de autoria do coletivo: "o ciberespaço se constitui como um espaço de construção de autores anônimos, coletivos e solidários, lugar de onde emergem novas discursividades, que se propóem a pensar os sentidos e os sujeitos em sua relaçấo com a língua, a cultura e a história. A noção de autoria na (re)escrita hipertextual parece se diluir no espaço constituído pelo ciberespaço; assim, o sujeito-autor, na qualidade de enunciador, assume uma posição determinada (por condiçôes sociais e ideológicas) revelando, a partir da unidade que tenta conferir ao seu texto, que é parte de um hipertexto, a sua própria unidade enquanto sujeito" (p. 81). Além de uma nova concepção autoral, há que se pensar, também, numa nova concepção da própria literatura, agora pensada "náo apenas fora do papel, mas também, principalmente, fora do cânone, fora da voz institucionalizada" (p. 82). O resultado de todo esse processo, conforme o autor, é a ascensão da cultura marginal, assinalando o ciberespaço como "lugar de ruptura e de quebra entre a cultura hegemônica e a cultura de margem" (p. 83).

Especificamente sobre a Literatura de Fã, o autor procura resgatar seus primórdios, com o aparecimento dos fanzines (as revistas de fã), a partir da década de 1930-1940, nos Estados Unidos (no Brasil, os primeiros datam da década de 1960), até a constituição da fanfiction (grosso modo, a "cultura de fã na internet", p. 100) e sua produção correspondente - as fanfics (histórias alternativas em prosa escritas por fấs de uma determinada série ou obra). Em geral, trata-se de uma produção que procura "suprir as necessidades que a cultura hegemônica suprimiu e negou às classes minoritárias" (p. 103), resultando na criaçáo de produtos culturais derivados. Trata-se, ainda, de um fenômeno próprio da chamada cultura participatória (participatory culture), termo utilizado para designar "uma cultura na qual fâs se apropriam de produtos culturais, do conceito de seus personagens e os reproduzem, modificando sua história e criando produtos derivados" (p. 105). Nesse contexto, os autores de fanfics deixam de ser meros consumidores e se tornam 
produtores, transformadores e agentes culturais, originando produtos culturais híbridos e descentralizados.

$\mathrm{O}$ autor expôe alguns tipos de fanfiction, além de discutir o estatuto de literatura dessa produção, lembrando que se trata de uma produção que questiona os conceitos de originalidade, cânone, autoria, leitor etc., destacando sua condição de arte marginal. Finalmente, é apresentada uma pesquisa exploratória, tendo como objeto de estudo as fanfics brasileiras que utilizam, como meio de produção e divulgaçáo, as comunidades sediadas na plataforma do Orkut e em sites e blogs feitos com essa finalidade, estudando o perfil dos escritores e das comunidades, o perfil dos sites, as produçóes etc.

Para quem quer se inteirar não apenas dos caminhos e descaminhos que o mundo virtual percorre atualmente, mas também sobre como se dá a interação entre esse universo e a cultura - gerando a chamada cibercultura -, o livro de André Neves é mais do que um bom começo, trazendo, ainda, uma análise percuciente do que se convencionou chamar fanfiction. 